\title{
Construction of computer specialty core competence and practical system in new era
}

\author{
Xiaodong Su, Hui Li, Yuru Zhang, Ming Zhao \\ School of Computer and Information Engineering, Harbin University of Commerce, Harbin, China \\ hrbcu_lh@163.com
}

Keywords: Specialty Core Competence; Big Data; Artificial Intelligence; Practical Teaching

\begin{abstract}
In the complex engineering environment caused by industry evolution and technology elimination, this paper analyzes the construction direction of the core competence of computer science. The connotation and mode of the ability cultivation of computer system would be expounded, and the method of the cross integration of big data and artificial intelligence in computer science has been presented.
\end{abstract}

\section{Introduction}

Today, need for higher education, scientific knowledge and talent people is more urgent. The new thought and new model of engineering education is called by new economic development strategy and new advantages in international competition, and strategic task of industrial revolution will be met. Both engineering education professional certification widely and new engineering construction are trying to explore the new thought and new model of talent training. With the rapid development of Big Data and Artificial Intelligence, unprecedented complex engineering environment should be faced by college graduates. In the new era, facing new opportunities and challenges, how to build the core competence of the computer specialty is very critical.

\section{Rebuild the core competence of computer specialty}

For Big Data, it should be associated with Artificial Intelligence. AI is a process of data analysis and application, and data is the precondition and basis of AI. There is an inevitable connection between Big Data and AI in dealing with engineering problems, and the basic knowledge system of computer science is the theoretical basis of Big Data and AI. The combination of Big Data and AI is the correct choice for the core capability of computer science in the new era. Big Data is also produced by "Internet of Things", and we should give "Internet of Things" back to the internet of things engineering.

Based on the core competence of computer system capability has been established, the cross fusion of Big Data and AI has been the new core. On the basis of solid ability of computer system, the teaching content and practice case would be keep synchronized with enterprise and industry. At last, the core of computer specialty ability and competitiveness will be formed.

\section{Computer system capacity training and practical system construction}

In a long time, computer language courses have been added to the curriculum system in the second undergraduate colleges prominently. This "soft" curriculum system loses its original basis, and fails to cope with the complex engineering environment. Training of computer system ability should be strengthed to carry out software and hardware collaborative design. CS2013 also requires attention to the coherence and systematicness of knowledge to organize the course content. The knowledge area of System Fundamentals (SF) was added in CS2013 particularly [2]. The integration of curriculum knowledge in various fields has been emphasized in CS2013, and the systematic and comprehensive 
ability cultivation should be more important. The ability of computer system is the most basic ability of computer professionals, and precondition of the integration of Big Data and Artificial Intelligence.

\subsection{Computer system capability and connotation}

Computer system capability refers to the ability to recognize and design computer systems. The training process can be divided into five stages or levels: cognition computer system, analysis computer system, design computer system, realization computer system and optimization computer system. Its connotation includes not only cognitive ability and analytical ability, but also comprehensive ability, practical ability, innovation ability, teamwork ability and self-learning ability. Its connotation includes not only cognition ability and analysis ability, but also comprehensive ability, practical ability, innovation ability and teamwork ability. Theoretical curriculum system and practical curriculum system are required to achieve systematic curriculum system.

\subsection{Construction of computer system capability training practical}

Courses to cultivate the ability of computer system include: "Digital Logic", "Principles of Computer Composition”, "Embedded Systems”, “Computer System Structure” hardware courses, and “OOP(object-oriented programming)”, "Fundamentals of Compiling”, "Fundamentals of Disk Operating System” software courses. The most important core is to establish a set of practical system that runs through the whole training process. It should be integrated with theory, experiment, curriculum design and graduation design. Practical teaching is so important for computer system. It is the most effective implementation to establish a complete practical system that runs through the whole training process.

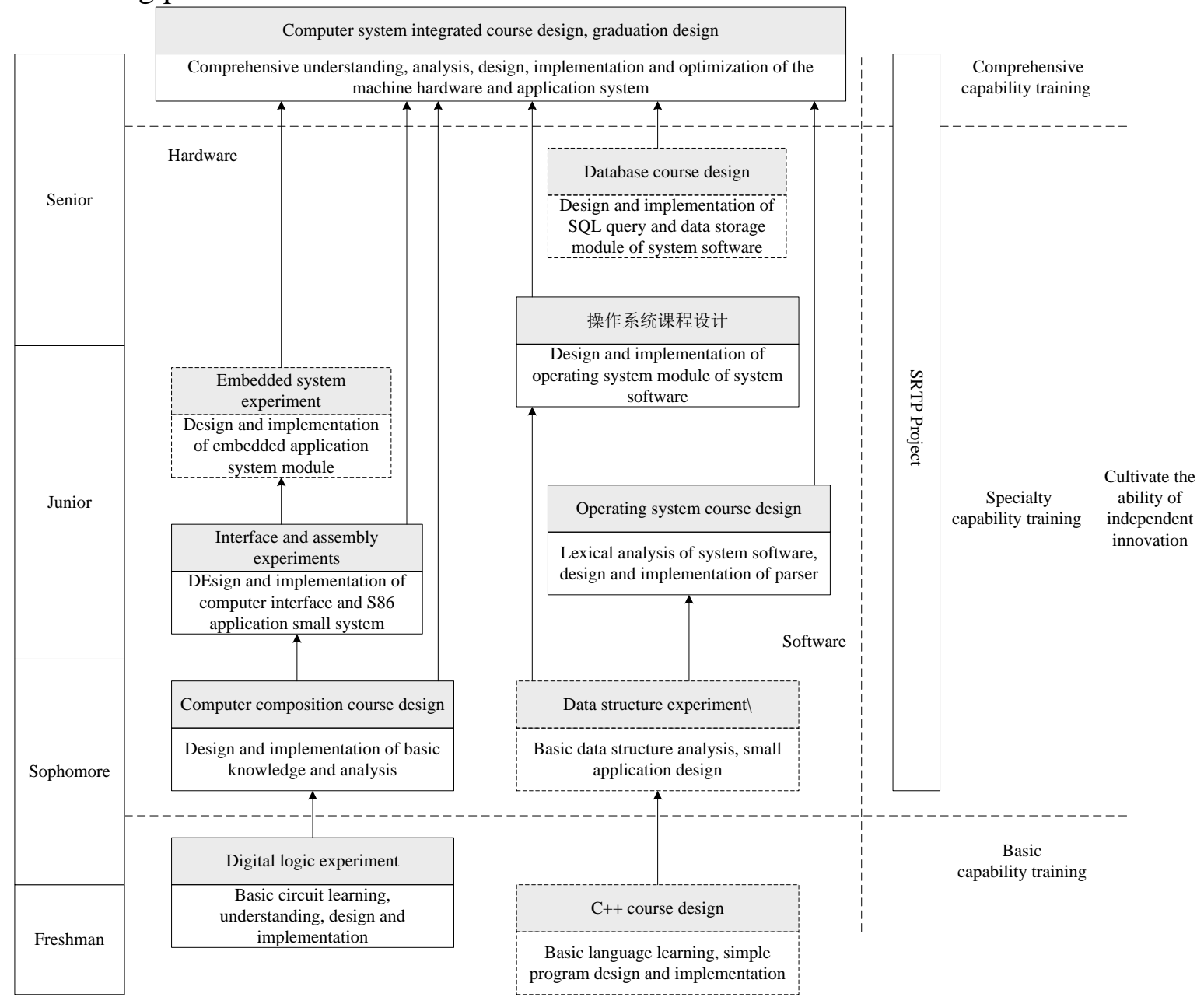

Figure.1 Structure of computer system capabiligy

The construction of the practical system includes the practical goals and general plans, practical courses and basic tasks, specific tasks and experimental handouts, the outline of the experimental 
courses. Fig. 1 describes the practical system architecture of computer system capacity training from southeast university [2]. The core of practical system is the practical course built by the curriculum system, and extension part which plays an auxiliary role in core courses. Each module is given in two parts, the course and the basic tasks. These modules are functional design sub-tasks in software experiments, and function component design sub-tasks based on IP core in hardware experiments.

The problems would be avoid by the practical system structure established in the way above:

1) The content of experimental courses are independent;

2) Practical role of overall design and optimization of the computer system is lacking;

3) Experimental equipment used in various courses is not the same;

4) Due to the reasons of experimental equipment (especially hardware-related experiments), students can only conduct experiments in the laboratory at fixed time [2].

\section{Cross integration of Big Data and AI}

Core concerns of talents training has divided as profession in the new industrial environment, and the knowledge of the traditional education has been gradually replaced by the applied education. The evolution direction of higher education reform is that knowledge is oriented to points. The knowledge application is oriented to complex engineering problems, and the correct application of knowledge is oriented to output.

The professional basic courses of Big Data include: "Development of Jave Web", "Linux Operating System”, “MySQL Database”, “Data Science and Big Data Technology”. The professional core courses of Big Data include: "Distributed Computing Domain Hadoop", "Programming Fundamental of Python”, "Data Analysis and Mining Technology”, "Spark Big Data Programming Technology”, "Data Analysis and R Language Modeling”, "Data Analysis Theory and Practice” etc.

The professional basic courses of AI include: "Principle of Computer”, “Operating System”, "Fundamentals of Compiling”, "Data Structure”, "Programing Design”. The professional core courses of AI include: "Python and Data Mining”, "Machine learning”, "NLP (Natural Language Processing)", "Computer Vision” etc.

The basic mathematics courses include "Probability", "Linear Algebra”, "Numerical Analysis", "Discrete Mathematics". Fig.2 shows the curriculum system of cross fusion of Big Data and AI.

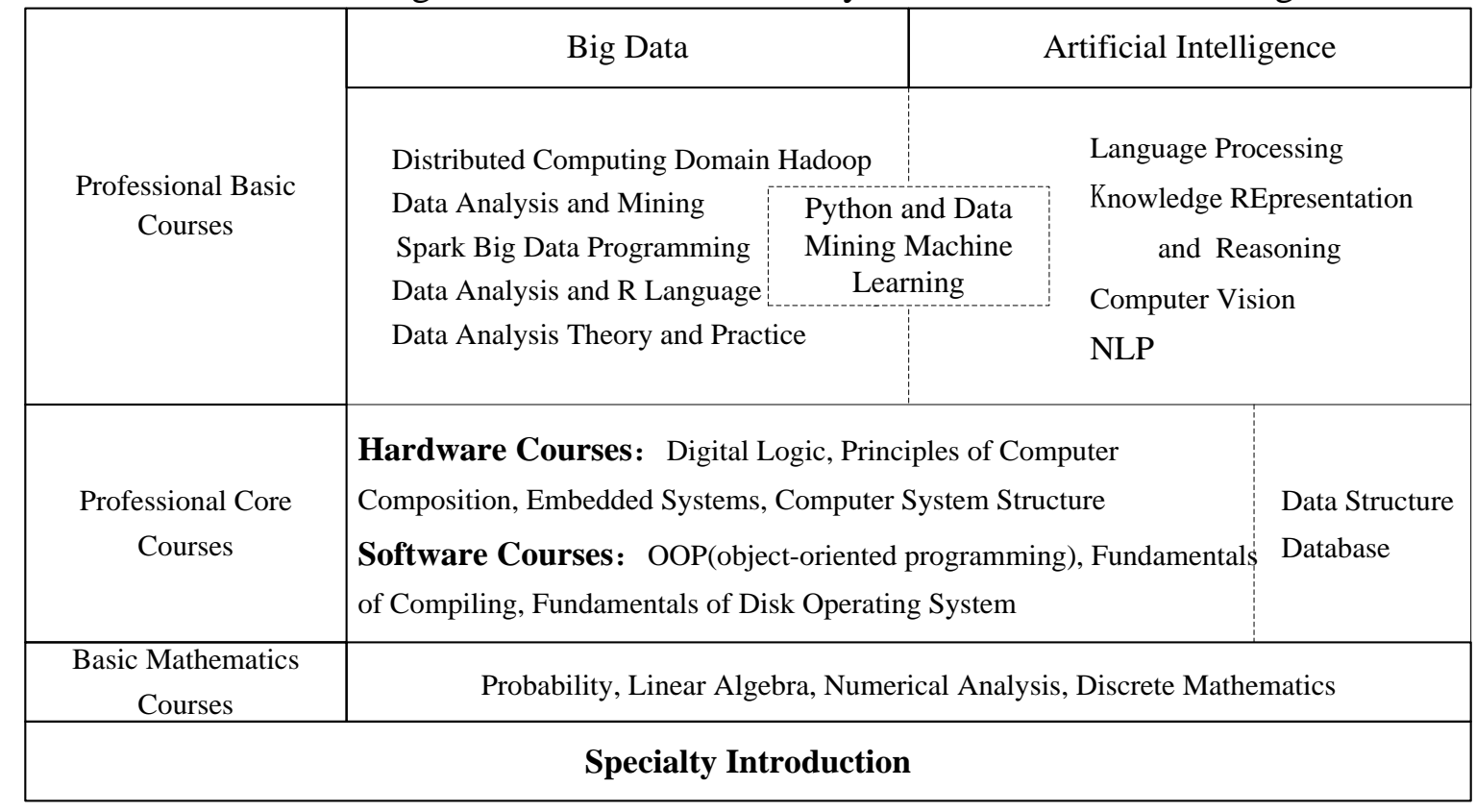

Figure.2 Curriculum system of cross fusion of Big Data and AI

The teaching plan of Big Data is centered on the core content of data collection, data processing, data storage, data analysis and data visualization. The actual projects of enterprises have been introduced. For example, to achieve brand recommendation by Big Data, to analyze agricultural 
internet of things farm data by Big Data. Skilled operation of commercial big data and open source Big Data technology have been focused on Big Data experiment [4-5].

Each unit of AI is relatively independent, so it is not necessary to explain the content in the order of teaching materials. Basic theories and practical methods are selected in the teaching content, instead of pursuing advanced theories and methods as postgraduate.

1) Engineering case teaching: AI has a very wide range of applications, which can be combined with the application examples in textbooks. Some application examples of AI that can be understood by undergraduates should be guide to solve engineering problems.

2) Project-based teaching: AI is very suitable for project-based teaching practice. Choose some simple application examples of AI to ask students for designing.

3) Research-based teaching: AI is a method to simulate people to solve problems, which is very suitable for research-based teaching.

The cross integration of Big Data and AI can effectively build the core competence of the computer specialty.

\section{Summary}

Cultivating computer system capability is the way for the computer specialty to "return to common sense, return to responsibility, return to original intention and return to dream". Based on the ability of computer system, it is one of the reasonable ways to build the core ability of cross integration of Big Data and AI in this new era. Practice is the process of testing truth, cultivating ability, and producing innovative thought and methods.

\section{Acknowledgements}

This work was financially supported by Cooperative and Cooperative Education Project of Ministry of Education of the People's Republic of China (201601023031, 201702029029, 201702064010), Teaching Reform Research Projects of Heilongjiang Education Department (SJGY20170055, SJGY20170075), Teaching Reform Research Projects of Harbin University of Commerce (SJXM2018A004, HSDJY014), Natural Science Foundation of Heilongjiang Province of China (F2015045), University Nursing Program for Young Scholars with Creative Talents in Heilongjiang Province (UNPYSCT-2016063) and Science Foundation of Harbin Commerce University (17XN060).

\section{References}

[1] Jinping Xi. Speech delivered at the seminar of teachers and students of Peking University, China 1 (2018)

[2] Quansheng Yang etal. Construction of a computer system practice platform that combines theory with practice. Computer education. Vol.33 No.1 (2018)

[3] Baosheng Chen. Emphasizing the "four regression" of universities. China (2018)

[4] Yan Gaizhen, Xu Chaoshen, Li Shuangxi. Exploration on the Engineering Education Oriented Electronic Information Specialty Construction. academic research.

[5] LIU Chun-ling, HE Ting, LU Hai-tian, WANG Chun-wu. Construction and practice of the course groups with different orientations in electronic information engineering major. Journal of Science of Teachers College and University (2018) 